\title{
Compromisso Social da Psicologia e Sistema Único de Assistência Social: Possíveis Articulações
}

\author{
Alessandra Xavier Miron \\ Neuza Maria de Fátima Guareschi \\ Universidade Federal do Rio Grande do Sul, RS, Brasil. \\ Universidade Federal do Rio Grande do Sul, RS, Brasil.
}

\begin{abstract}
Resumo: O presente artigo apresenta reflexões acerca do Compromisso Social da Psicologia, partindo da sua presença nas referências técnicas publicadas pelo Sistema Conselhos para atuação dos psicólogos no Sistema Único de Assistência Social - SUAS e da análise dos cadernos de deliberações produzidos a partir dos Congressos Nacionais de Psicologia. Através dos marcadores Compromisso Social, Direitos Humanos e Políticas Públicas, buscamos evidenciar a complexidade que atravessa as práticas psicológicas no campo das políticas sociais públicas na medida em que a garantia de direitos passa a se configurar como objeto para a profissão. Pretendendo contribuir para as problematizações sobre o tema, propomos a institucionalização do discurso do Compromisso Social, os processos de judicialização da vida e a atualização de compromissos entre Psicologia e Estado como movimentos que tem efeitos significativos na atuação profissional de psicólogos no SUAS.
\end{abstract}

Palavras-chave: Compromisso Social, Congresso Nacional de Psicologia, Sistema Único de Assistência Social.

\section{Social Commitment of Psychology and Unified Social Assistance System: Possible Articulations}

\begin{abstract}
This article presents reflections about the Social Commitment of Psychology, starting from its presence in the technical references published by the System Councils for the performance of psychologists in the Unified Social Assistance System - SUAS and the analysis of the books of deliberations produced from the National Congresses of Psychology. Through the indicators "Social Commitment", "Human Rights" and "Public Policies", we seek to highlight the complexity that crosses the psychological practices in the field of public social policies in so far as the guarantee of rights is now configured as an object for the profession. Intending to contribute to the problematizations on the subject, we propose the institutionalization of the discourse of Social Commitment, the processes of judicialization of life and the updating of commitments between Psychology and State as movements that have significant effects on the professional performance of psychologists in SUAS.
\end{abstract}

Keywords: Social Commitment, National Congress of Psychology, Unified Social Assistance System. 


\title{
Compromiso Social y Sistema Único de Asistencia Social: Posibles Articulaciones
}

\begin{abstract}
Resumen: El presente artículo presenta reflexiones acerca del Compromiso Social de la Psicología partiendo de su presencia en las referencias técnicas publicadas por el Sistema de Consejos para actuación de psicólogos en el Sistema Único de Asistencia Social - SUAS y del análisis de los cuadernos de deliberaciones producidos a partir de los Congresos Nacionales de Psicología. Por medio de los marcadores "Compromiso Social", "Derechos Humanos" y "Políticas Públicas", buscamos evidenciar la complejidad que atraviesa las prácticas psicológicas en el campo de las políticas sociales públicas en la medida que la garantía de derechos pasa a configurarse como objeto para la profesión. Pretendiendo contribuir para las problematizaciones sobre el tema, proponemos las institucionalización del discurso del Compromiso Social, los procesos de judicialización de la vida y la actualización del compromiso entre Psicología y Estado como movimientos que tienen efectos significativos en la actuación profesional de los psicólogos en el SUAS.
\end{abstract}

Palabras clave: Compromiso Social, Congreso Nacional de Psicología, Sistema Único de Asistencia Social.

\section{Introdução}

Pesquisar em Psicologia desnaturalizando teorias e interrogando as práticas produzidas pelo próprio discurso psicológico a fim de visibilizar como elas funcionam, quais as suas condições de emergência e legitimação, procurando desacomodar esta ciência a partir de leituras da obra de Michel Foucault é o movimento de onde partem as análises que sustentam a escrita do presente artigo. A articulação entre Psicologia Social e Políticas Públicas é considerada, portanto, não como evidência, mas como campo problemático, localizado em um processo contemporâneo de governamentalização da vida através do qual a gestão das condutas dos indivíduos vai se tornando parte das ações cotidianas de todos os cidadãos, especialmente quando se pensa no contexto das políticas sociais. Neste, não faltam prescrições e mecanismos de controle sobre como usar o benefício, como viver em família, como conviver na comunidade, como criar vínculos, como trabalhar, como estudar etc. Diversos são os pesquisadores (Lockmann, 2013; Macedo, 2007; Pereira, 2013; Trein, 2012) que têm se dedicado a estudar como estas relações se estabelecem nas políticas de Assistência Social, as quais nos últimos dez anos, especialmente, se ampliaram e adquiriram novos contornos enquanto espaço de atuação para as(os) psicólogas(os) no país.

Inicialmente é preciso lembrar que a construção e a implementação do Sistema Único de Assistência Social - SUAS (Brasil, 2005), apontada pela Política
Nacional de Assistência Social - PNAS (Brasil, 2004), são os processo que visam garantir a Assistência Social como política pública, de acordo com as deliberações da IV Conferência Nacional de Assistência Social (2003) para materializar as diretrizes da Lei Orgânica de Assistência Social - LOAS (Brasil, 1993) e transformar em ações os pressupostos da Constituição de 1988 (Brasil, 1988). Iniciada há quase de três décadas, portanto, a mudança de um paradigma assistencialista, meritocrático e caritativo de assistência para um paradigma de garantia de direitos sociais, universalização dos acessos e responsabilidade estatal, afirmado pela Lei no 12.435 (Brasil, 2011), opera no âmbito da Assistência Social brasileira mesclando elementos de um passado recente às novas políticas, em proporções que variam de acordo com as especificidades de cada território. A maioria dos municípios do país, entretanto, já está habilitada no SUAS e, assim, teoricamente comprometida com seus princípios - supremacia do atendimento às necessidades sociais, universalização dos direitos sociais, respeito à dignidade do cidadão, igualdade de direitos no acesso ao atendimento e divulgação ampla dos serviços, programas e benefícios - bem como, com suas diretrizes - descentralização político administrativa, participação da população, primazia da responsabilidade do Estado e centralidade na família -, tomando como público-usuário "cidadãos e grupos que se encontram em situações de vulnerabilidade e riscos" (Brasil, 2005, p. 33). 
Cientes de que as próprias noções de risco e vulnerabilidade podem e devem ser colocadas em questão, mas de que essa discussão vai além do que nos propomos nesse artigo, apontamos ainda que, de acordo com a PNAS, dois tipos de proteção devem ser assegurados a este público - a proteção social básica e a proteção social especial - cada qual a partir de unidades públicas específicas para a oferta dos serviços apresentados na Tipificação Nacional dos Serviços Socioassistenciais (Brasil, 2009). Na proteção social básica, que tem por objetivo prevenir situações de risco e fortalecer vínculos familiares e comunitários, encontram-se os Centros de Referência em Assistência Social - CRAS. Na proteção social especial de média complexidade, que se destina ao atendimento de situações de risco pessoal e social envolvendo violação de direitos, com preservação de vínculos familiares e comunitários, encontram-se os Centros de Referência Especializados em Assistência Social - CREAS. Na proteção social especial de alta complexidade, que se destina a situações que exigem proteção integral em função de rompimento dos vínculos familiares e/ou comunitários, encontram-se diferentes unidades, como albergues, repúblicas, casas de passagem e casas lar. Todas as unidades devem contar com equipes de referência definidas pela Norma Operacional Básica de Recursos Humanos do Sistema Único de Assistência Social - NOB-RH/SUAS (Brasil, 2006), as quais incluem as(os) psicólogas(os) entre os profissionais.

Pensando sobre as articulações que possibilitam a emergência desta política pública como campo de atuação nesse momento histórico específico e sobre os movimentos que contribuíram para a inclusão das(dos) psicólogas(os) neste quadro, gostaríamos de ir além de algumas metáforas comumente usadas para definir esse processo como "caímos de paraquedas" ou "estamos sendo chamados", a fim de reconhecermos (ou conhecermos) um movimento ativo da profissão em direção a este campo. Neste sentido, destacamos aqui o projeto denominado Banco Social de Serviços em Psicologia ${ }^{1}$, construído e desenvolvido no período de maio de 2003 a agosto de 2005, a partir do Conselho Federal de Psicologia (CFP) e alguns Conselhos Regionais. Através dele, o Sistema Conselhos entrou em contato com ministérios e outros órgãos públicos para oferecer projetos referentes a seis políticas públicas: nas áreas de geração de renda; atenção a crianças e adolescentes em situação de risco social; saúde mental e desinstitucionalização psiquiátrica; segurança pública e políticas de reinserção social de encarcerados; processos de aprendizagem e escolarização; e políticas públicas de comunicação social de controle da mídia e fortalecimento da cidadania. A maioria, portanto, relacionada a políticas de Assistência Social.

De acordo com o relatório publicado ao final do projeto (Conselho Federal de Psicologia, 2005), essa experiência possibilitou à profissão dar visibilidade a práticas menos conhecidas, participar de políticas que visavam melhorar as condições de vida do país e abrir novos canais de negociação com o Estado sobre as possibilidades de exercício profissional do psicólogo de maneira que o encerramento do projeto apontou outros lugares possíveis para a Psicologia no Brasil. Não podemos dizer que antes disso as(os) psicólogas(os) não estivessem presentes em políticas de Assistência Social, mas sim, que a implementação da NOB-RH/SUAS (em 2006, um ano após o fim do projeto citado) garantindo a inclusão das(dos) psicólogas(os) nas equipes de referência estabeleceu um marco na inserção das(dos) profissionais neste campo - que hoje contam com cerca de 14 mil profissionais em seu quadro, conforme fala da Secretária Nacional de Assistência Social Denise Colin, na abertura do VIII Congresso Nacional de Psicologia (Conselho Federal de Psicologia, 2013). Esse aumento do número de empregos para psicólogas(os) em políticas públicas, em especial no SUAS, tem dado visibilidade às discussões sobre a descontextualização da prática profissional, evidenciada em diferentes espaços acadêmicos e profissionais.

De acordo com Oliveira e Amorim (2012), assim como ocorreu na conformação do campo da saúde pública nos anos 1990, essa inserção no SUAS tem se dado mais em função dos limites impostos pelo mercado de trabalho do que por uma conscientização profissional quanto à sua função junto às camadas mais pobres da população, em um movimento que direciona a categoria para novos espaços de atuação, capazes de absorver a mão de obra, mas sem que se tenha construído um modelo de trabalho adequado ao contexto, persistindo a ideia de levar psicoterapia aos mais pobres, em uma tendência à reprodução dos modelos dessa atuação da clínica privada independente dos objetivos da política social na qual se insere.

\footnotetext{
${ }^{1}$ Para mais informações sobre este projeto sugerimos acesso ao vídeo CFP - Banco Social de Serviços em Psicologia disponível em: https://www.youtube.com/watch?v=Pa8sOYeoNUs.
} 
Nesse sentido, a resposta oferecida pelo Sistema Conselhos de Psicologia tem sido a produção de referências técnicas para atuação das(dos) psicólogas(os) em diversas políticas públicas, a partir do Centro de Referência Técnica em Psicologia e Políticas Públicas CREPOP (Oliveira, 2012). Através deste artigo buscamos contribuir para a problematização sobre o tema partindo da análise do discurso do Compromisso Social da Psicologia presente nestas orientações técnicas produzidas pelo Sistema Conselhos direcionadas às(aos) profissionais que atuam no SUAS.

\section{Método}

Problematizar, discutir teoricamente, refletir criticamente sobre as relações entre Psicologia Social e Políticas Públicas evidenciadas pela atuação de psicólogos na PNAS implica em um estudo mais atento dos saberes que têm circulado como verdades, constituído as práticas e produzido sujeitos - psicólogos e usuários - neste campo. Reconhecendo o alcance e a dimensão que assumem as referências técnicas publicadas pelo Centro de Referência Técnica em Psicologia e Políticas Públicas (Crepop) neste cenário, partimos da leitura do material produzido para encontrar as primeiras pistas neste sentido.

De acordo com o Conselho Federal de Psicologia (2007), o Crepop tem como função principal a produção de informação qualificada visando ampliar a capacitação das(dos) psicólogas(os) na compreensão das políticas públicas de modo geral e na compreensão teórico-técnica do processo de elaboração, planejamento e execução das mesmas. Além disso, ele se configura como ferramenta capaz de criar discurso para diálogo com o Estado e para divulgação da Psicologia à sociedade. Desde sua criação, funciona como "um órgão operacional que se sustenta no compromisso social como eixo político central, posicionando-se pela garantia dos direitos humanos" (Reis, Giugliani, \& Pasini, 2012, p.150). Sendo assim, este posicionamento é evidenciado em todas as referências técnicas produzidas pelo Sistema Conselhos relativos à atuação no SUAS - como podemos ver nos exemplos a seguir:

A inserção do(a) psicólogo(a) nas políticas públicas cresceu muito nos últimos dez anos. Essa atuação foi acompanhada pela construção, na Psicologia, do compromisso social, com a participação de psicólogos e psicólogas de todo o país.
A partir dessa perspectiva, é valorizada a construção de práticas comprometidas com a transformação social, em direção a uma ética voltada para a emancipação humana (Conselho Federal de Serviço Social, 2007, p. 20).

Deve-se realizar uma prestação de serviços responsável pela execução de um trabalho de qualidade cujos princípios éticos sustentam o compromisso social da Psicologia. Dessa forma, a demanda, tal como é formulada, deve ser compreendida como efeito de uma situação de grande complexidade (Conselho Federal de Psicologia, 2009, p. 46).

O CFP considera as políticas públicas elementos centrais para a melhoria da qualidade de vida da população. Com essa visão, o CFP reforça o compromisso social da profissão em defesa da democracia e das políticas públicas (Conselho Federal de Psicologia, 2011, p. 07).

[...] a participação política das(os) psicólogas(os), o compromisso e a responsabilidade social da profissão em ações que afirmem uma rede de serviços destinados aos adolescentes em cada município, como a criação de estratégias de envolvimento dos adolescentes que cumprem medida socioeducativa em espaços de debate e conquista de seus direitos de cidadania (Conselho Federal de Psicologia, 2012, p. 41).

Mas, de que estamos falando quando falamos sobre compromisso social? Longe de ser um discurso intrínseco à prática profissional no país ou um atributo que caracteriza uma "psicologia do bem" e legitima qualquer prática a ele associada, o Compromisso Social da Psicologia foi construído a partir de uma relação de forças num campo historicamente dado. De acordo com Bock, Ferreira, Gonçalves e Furtado (2007), ele teve início no movimento de rompimento da profissão com sua tradição elitista e na necessidade de se construir um novo projeto na América Latina e no Brasil, especialmente a partir dos anos 1970, a fim de tornar a Psicologia acessível à maioria da população, com uma oferta de serviços e conhecimentos que contribuíssem para a construção de melhores condições de vida no país. Ou seja, ele entrou em cena como transgressão dos discursos vigentes, resistência às for- 
mas de poder hegemônicas, em direção a práticas de liberdade - como linha de fuga, no sentido apontado por Foucault (Prado Filho, \& Martins, 2007).

Passados alguns anos e ocorridas transformações na sociedade brasileira, surgem algumas questões: como esse discurso foi se transformando? Como foi se instituindo? Como circula hoje entre psicólogas(os)? Conforme lembram Moraes e Nascimento (2002), nas últimas décadas a sociedade de controle aprendeu a extrair comando e energia e a explorar justamente a produção incessante de vida dos movimentos de contestação à sociedade de normatização fazendo operar uma série de estratégias através das quais se utiliza provisória e parcialmente das subjetividades criadas, transformando-as em espelhos identitários que atraem o consumo e o comportamento. Portanto, em um momento onde cresce o número de psicólogas(os) trabalhando em políticas púbicas, o SUAS se configura como um dos espaços que mais acolhe profissionais atualmente, e as referências técnicas propostas pelo Sistema Conselhos orientam no sentido de uma prática que deve protagonizar movimentos de transformação social, cabe refletirmos sobre as questões levantadas.

Sem que isso signifique estar aquém ou além de uma adesão ou recusa de suas enunciações, como aponta Bicalho (2011), neste artigo interessa a problematização de nossas práticas e a reflexão sobre seus efeitos, os agenciamentos que produzem e atualizam. Assim, em nossos estudos, depois feito o mapeamento de algumas condições que possibilitaram o surgimento e a permanência de determinadas configurações da Psicologia no país, colocando em contato demandas da profissão e demandas do Estado em diferentes momentos históricos e criando condições para que o discurso do Compromisso Social se instituísse, foram eleitos os cadernos de deliberações produzidos a partir dos Congressos Nacionais de Psicologia como documentos através dos quais seria possível analisar esse processo e refletir sobre alguns de seus efeitos. Em especial, buscamos compreender as relações entre o Compromisso Social da Psicologia e as práticas dos profissionais que atuam no SUAS.

Para tanto, a proposta não foi de um tratamento exaustivo de todo o material nem a equitativa repartição cronológica do exame como fariam os historiadores ao estudar determinado período. Foram seguidas as diretrizes apontadas por Foucault no texto "A poeira e a nuvem" (1980/2012) quando se busca estudar um problema surgido em um determinado momento: escolha do material em função dos dados do problema, focalização da análise sobre os elementos suscetíveis de resolvê-lo, estabelecimento de relações que permitem esta resolução e, portanto, indiferença com a obrigação de tudo dizer - mesmo para satisfazer ao júri dos especialistas convocados. O trabalho assim concebido implica em "um recorte sobre pontos determinantes e uma extensão segundo relações pertinentes" (Foucault, 1980/2012, p. 320). Compartilhamos através da discussão que segue algumas das reflexões possibilitadas pelas análises empreendidas.

\section{Psicologia, ordem e progresso: encontros entre as demandas da profissão e as demandas do Estado}

A partir do pensamento de Michel Foucault sobre modos de veridcção, formas de governamentalidade e técnicas de subjetivação, pensamos o Compromisso Social da Psicologia na articulação destas três dimensões. Conforme Gros (2011), estas dimensões não são como partes distintas que precisam ser estudadas como domínios separados e Foucault insiste que a identidade do dizer filosófico está justamente numa estrutura de chamamento:

[...] nunca estudar os discursos de verdade sem descrever ao mesmo tempo sua incidência sobre o governo de si ou dos outros; nunca analisar estruturas de poder sem mostrar em que saberes e em que formas de subjetividade eles se apoiam; nunca identificar os modos de subjetivação sem compreender seus prolongamentos políticos e que relações com a verdade eles se sustentam (Gros, 2011, p. 306).

Assim, pensar o Compromisso Social da Psicologia enquanto discurso demanda olharmos para as forças que atravessaram a história da própria Psicologia no país. De acordo com Lopes (2005), ao remontarmos às concepções mais remotas referenciadas como pensamento psicológico, que antecederam ao estabelecimento da Psicologia no Brasil, desde o período pré-colonial (séculos XVI e XVII), podemos perceber que todo o conhecimento da época sobre fenômeno psicológico foi utilizado pelos representantes do poder para dominar a população indígena, normatizar seu comportamento e reprimir sua cultura.

Esses movimentos iniciais do Brasil-colônia se atualizam no Brasil-império, a partir do século XIX, 
quando a mudança da corte para o país cria a necessidade de formar quadros para garantir o aparato repressivo e administrativo do governo e são instituídos os primeiros cursos superiores. Nesse momento, aponta a autora, a produção de saber psicológico ocorre a partir da Medicina e da Educação, influenciada significativamente pelo pensamento europeu representante das correntes liberais e positivistas. A partir da década de 1920, a Psicologia passa a se dedicar às questões do trabalho na seleção, avaliação, prevenção de acidentes e higiene, assumindo junto a outras ciências a função de sustentáculo científico de novos métodos de administração demandados pelos empresários brasileiros diante do fortalecimento dos sindicatos, da difusão do ideário anarquista e, portanto, diante da necessidade de novas práticas de controle.

Do exposto, podemos compreender que uma das linhas de força que atravessa a história da profissão no país desde suas primeiras versões é a necessidade de manter determinada organização social. Outra, derivada desta, é a utilização de saberes psicológicos para identificar e corrigir comportamentos que fogem do que está estabelecido como padrão em determinado período. Também, a preocupação em atender interesses de grupos hegemônicos, contribuindo para a "exploração sem resistência". E, por fim, outra linha de força é constituída pela inspiração em referenciais estrangeiros sustentados em correntes de pensamento liberais e positivistas. Entendemos o conjunto dessas linhas de força como acontecimento que possibilita a emergência de uma Psicologia a serviço do Estado, em sintonia com o contexto histórico e social vigente.

Conforme aponta Leite (2008),

Também não podemos nos esquecer de que a Lei 4.119/62 foi aprovada no apagar das luzes de um governo democrático, tido pelas oligarquias dominantes como "comunista", e num momento em que as forças reacionárias, de direita, organizavam-se para derrubar o poder constituído, culminando no golpe militar de 1964 (Leite, 2008, p. 11).

Ou seja, aos movimentos de institucionalização da profissão no país, que culminam com a criação da profissão em 1962, seguem-se nove anos de silêncio que, de acordo com o mesmo autor, abrangem os piores anos do regime militar, produzindo intensa repressão política e amedrontamento das pessoas, desprotegidas nos seus direitos mais básicos. As(os) psicólogas(os), segundo ele, como as outras categorias profissionais, não estavam fora desse clima de constrangimento $\mathrm{e}$ medo. A própria criação dos Conselhos de Psicologia, carrega em sua Lei no 5.766/1971 muito do clima político daquele momento de forte ligação com o Estado, trazendo como função dos Conselhos "fiscalizar, orientar e disciplinar" o exercício da profissão.

Nos anos 1970, entretanto, alguns movimentos de ruptura e descontinuidade com relação ao percurso que a profissão vinha traçando no país começam a ganhar proporção. Ainda que hegemonicamente vigorasse a crença na legitimidade do controle da sociedade através de práticas psicológicas, no interior da profissão e em articulação com intelectuais de outras áreas, começaram a serem traçadas algumas linhas de fuga. Movimentos de militância possibilitaram diversas experiências de psicólogos junto aos movimentos populares, como faziam também outros profissionais das ciências humanas, desenvolvendo atividades como reuniões e discussões em torno das necessidades vividas pela população, levantamentos e descrições das condições de vida, assistência psicológica gratuita, participação em passeatas, mobilizações e abaixo-assinados que protestavam contra as precariedades das condições de existência e reivindicavam serviços básicos (Freitas, 2003).

Lembrando que este não era o entendimento predominante acerca da Psicologia e sua função, teve início uma luta não apenas para deselitizar a Psicologia como também, pelo envolvimento e participação política da profissão. Diante disso entendemos que a Psicologia a serviço do Estado se opõe, inicialmente, a esse outro conjunto de forças criado pelas experiências com comunidades, pela articulação com outros saberes, pela politização das discussões dentro da profissão. A articulação desse conjunto de forças é compreendida aqui como acontecimento que possibilita a emergência uma Psicologia comprometida com a garantia de direitos. Os jogos de poder entre essas duas Psicologias são condição de possibilidade para o discurso do Compromisso Social da Psicologia se instituir na década seguinte.

Entendemos que, a partir de uma descontinuidade no processo de institucionalização da profissão que se estabelecia, de um movimento de ruptura com posições até então predominantes dentro da categoria, engendrados em um cenário de transformação do cenário político nacional, são criadas as possibilidades para que temas como política, direitos sociais, 
cidadania, políticas públicas, entre outros a estes relacionados, passem a ser de interesse para as(os) psicólogas(os), marcando de forma sutil e dispersa a construção da garantia de direitos como um objeto para a profissão, a partir das forças presentes naquele momento histórico e dos problemas que se tentava responder. De acordo com Scarparo e Guareschi (2007), a participação de intelectuais em movimentos de emancipação política era crescente e uma expressiva quantidade de psicólogas(os) passou a questionar o papel e a responsabilidade social da Psicologia, relacionando-os aos aspectos sociais e políticos da sociedade brasileira naquele momento.

Assim, ao mesmo tempo em que se instituíam o Conselho Federal e os Regionais da profissão, emergiam manifestações que procuravam desmistificar as teorias psicológicas, bem como, discutir suas origens ideológicas e os valores subjacentes às lógicas postuladas. Neste mesmo período, alguns sindicatos de Psicologia também começaram a se opor aos processos que vinham se instituindo, aos compromissos que a profissão vinha mantendo com a elite do país, e começaram a ter visibilidade outros ideais com relação aos rumos da profissão, formas de atuação e espaços para a Psicologia na sociedade brasileira.

Estes grupos começaram também a ocupar os Conselhos de Psicologia, ampliando o alcance dos debates e reflexões acerca destas entidades enquanto representativas da profissão, na medida em que sua estrutura era hierarquizada e federativa, ou seja, a direção da entidade era montada a partir de indicações dos Conselhos Regionais e as(os) psicólogas (os) ficavam distantes da indicação dos conselheiros do CFP. Intensificaram-se, então, os debates e reflexões acerca do papel da(do) psicóloga(o) na sociedade e da função social dos Conselhos sendo colocada a necessidade da revisão da estrutura dos Conselhos de Psicologia no Brasil na direção de formas democráticas de se construírem deliberações no Sistema Conselhos de Psicologia.

Um dos efeitos destas discussões foi a constituição do Congresso Nacional da Psicologia (CNP) como instância máxima de caráter deliberativo, responsável por estabelecer diretrizes políticas para a atuação da autarquia para o triênio subsequente à sua realização, devendo ser realizado a cada três anos, sendo local de articulação política e inscrição de chapas para o Conselho Federal. Em âmbito regional, esse processo se dá através dos Coreps - Congressos Regionais de Psico- logia (Albanezi, 2008). Em função disso, acreditamos que os Congressos Nacionais de Psicologia possuem importância enquanto campo no qual, a partir de procedimentos internos e externos que regulam o acontecimento discursivo (Foucault, 1970/2012), o Compromisso Social da Psicologia se legitima enquanto verdade para a categoria profissional, ainda que existam limitações importantes a serem consideradas no que se refere à participação dos profissionais nos processos coletivos de debate e decisões - articulados aos sentidos da democracia representativa no país.

\section{Congresso Nacional de Psicologia e compromisso social: a institucionalização da militância}

A análise dos cadernos de deliberações permite pensar que a partir do III CNP (Conselho Federal de Psicologia, 2014) é que o Compromisso Social da Profissão começa a circular de forma mais ampla entre as (os) psicólogas (os), na medida em que a discussão das políticas públicas assume destaque - o Sistema Conselhos passa a se comprometer com a ampliação do mercado de trabalho para a(o) psicóloga(o), dentro da perspectiva de atender às demandas da sociedade. Pode se entender que esta edição criou as condições para que no IV CNP (Conselho Federal de Psicologia, 2001) o discurso assumisse centralidade enquanto proposta de construção coletiva para a profissão, estando evidente desde seu tema: "Qualidade, Ética e Cidadania nos Serviços Profissionais: construindo o compromisso social da Psicologia". Nas edições seguintes, ele ganhará consistência através duas vias principais: a defesa dos Direitos Humanos e das Políticas Púbicas.

Do exposto é possível compreender que, a partir deste momento, o Compromisso Social da Psicologia passa a ser a perspectiva ético-política a partir da qual todos os temas são abordados. Ou seja, que passa a ser defendida pelo Sistema Conselhos e, portanto, para a profissão, a perspectiva de uma Psicologia que coloca suas práticas a serviço da transformação social, de uma ética voltada para a emancipação humana, da defesa da democracia e das políticas públicas e da inserção em espaços de debate e conquista de direitos de cidadania. A Psicologia que toma como objeto a garantia de direitos da população - conforme evidenciado mais tarde no tema do VIII CNP (Conselho Federal de Psicologia, 2013): "Psicologia, Ética e Cidadania: práticas profissionais a serviço da Garantia de Direitos". Esse processo ocorre não porque o discurso 
do Compromisso Social seja verdade universal, mas porque construído enquanto discurso verdadeiro em um determinado momento da profissão do país, através de diferentes mecanismos de regulação que se convertem em teses e propostas debatidas e votadas pela categoria profissional representada.

Ao mesmo tempo em que esse processo de institucionalização do discurso permite visibilidade a uma perspectiva crítica da profissão, em um movimento de transgressão dos discursos profissionais hegemônicos e de resistência aos jogos de poder que colocam a Psicologia a serviço das elites e do Estado, é importante questionar se, em alguma medida, não reduz potência desestabilizadora que ele carregava em seus primeiros anos, inviabilizando o movimento em direção a práticas de liberdade. Nesse sentido, apontamos para o fato de que, após a redemocratização do país, mas especialmente a partir do Governo Lula (2003-2010), muitos militantes que até então estavam engajados nos movimentos sociais e nas lutas pelos direitos da população, entre os quais muitos psicólogos, hoje fazem parte de instituições governamentais, de entidades conveniadas com o poder público etc. E que isso não se converte, necessariamente, em ações que beneficiem os públicos pelos quais antes lutavam, na medida em que para ocupar lugares estratégicos, muitas alianças operam, muitas negociações são necessárias, restringindo, paradoxalmente, a possibilidade de atuação política contrária aos interesses hegemônicos.

Esse movimento, além de não resultar no efeito esperado em termos de transformação social - ou pelo menos, ainda não - faz com que haja um esvaziamento dos espaços de militância e controle social, despotencializando estratégias coletivas de resistência aos mecanismos de governamento contemporâneos. Diante disso, entendemos que a institucionalização da militância é um aspecto do novo cenário institucional brasileiro a ser considerado quando se pensa nas relações atuais entre Psicologia e Estado. Não significa dizer que psicólogas(os) não devem ocupar estas posições e estes espaços, mas que é necessária certa reflexão crítica sobre os efeitos das parcerias que se estabelecem a partir deles, atentando para o que parece ser um processo gradual de cooptação da resistência e de um novo alinhamento entre a Psicologia e o Estado, operando agora de uma maneira bem mais complexa porque sustentado em discursos internacionalmente avançados, como no caso dos Diretos Humanos, e em bandeiras de luta de vários movimen- tos sociais, como as Políticas Públicas - o que favorece sutis estratégias de controle de parcelas da população em nome da proteção e do cuidado.

Por outro lado, lembramos que, de acordo com Gros (2004), no final dos anos 1970, Foucault já apontava em seus estudos que o Estado moderno combina as estruturas de uma governamentalidade pastoral com as da razão de Estado, enquadrando populações e identificando os indivíduos, sendo o Estado-providência o prolongamento último desse duplo controle no que concerne à prosperidade e à quantidade das populações, à saúde e à longevidade dos indivíduos. Para ele, portanto, essa dupla vocação do Estado conduz a lutas vãs e extraviadas na medida em que a oposição entre Estado e o indivíduo e seus interesses, ou entre Estado e a comunidade e suas exigências é casual, pois se trata em ambos os casos daquilo que o Estado produz, regula, domina. Nesse sentido, é possível pensar a articulação entre Psicologia e Estado como uma estratégia de fortalecimento dos espaços democráticos e um meio para se construir movimentos de resistência, na medida em que a oposição ao Estado consiste, no fim das contas, em uma ilusão.

Além disso, a análise dos cadernos de deliberações também proporcionou a reflexão sobre em que medida a institucionalização do discurso foi acompanhada por ações na direção de seus princípios. Ao estudar as publicações da revista "Psicologia: Ciência e Profissão" sobre o tema, Lopes (2005) verificou que embora fosse demonstrada uma preocupação da(o) psicóloga(o), em todas as áreas, com as condições de vida da população geral, com os problemas relativos à estrutura social e com as relações sociais, poucas ações concretas foram geradas a partir dessas preocupações e, tampouco, foram propostos novos referenciais teóricos orientados a essa concepção. Conforme a autora, quando o assunto é Compromisso Social, a atitude principal das(os) psicólogas(os) que divulgam seus trabalhos na referida revista tem sido a modificação na concepção que têm de sujeito, passando de uma visão naturalizada dos fenômenos psicológicos para uma visão onde os sujeitos, e consequentemente, os fenômenos psicológicos, são constituídos de modo concreto, histórico e social.

Segundo a autora, fica evidente que as(os) psicólogas(os) desejam promover mudanças visando a transformação social, para a emancipação dos seres humanos e melhorias das condições de vida da população, entendem que é essencial a promoção dessas mudanças, no entanto, essa intenção não se 
objetiva em práticas outras além das discursivas - o que não apenas se mostra insuficiente, como também, "pode servir para escamotear a velha ideologia da neutralidade dos psicólogos e da psicologia" (Lopes, 2005, p. 90). Ou seja, o Compromisso Social da Psicologia parece ter se tornado o discurso "politicamente correto" da profissão e os efeitos disso ainda buscamos compreender. Para agregarmos outros elementos a esta problematização, compartilhamos na sequência seu desdobramento no que se refere aos Direitos Humanos e às Políticas Públicas.

\section{Congresso Nacional de Psicologia e direitos humanos: práticas profissionais a serviço de quem?}

A partir dos cadernos de deliberações, fica evidente que os Direitos Humanos passam a ser pauta específica nos Congressos Nacionais de Psicologia também a partir do IV CNP (Conselho Federal de Psicologia, 2001), através de teses referentes à questão indígena, à reforma psiquiátrica, à diversidade de raça, gênero e orientação sexual, entre outras, sendo esta pauta ampliada nas duas edições seguintes: no V CNP (Conselho Federal de Psicologia, 2004) ganham destaque teses referentes à luta contra diversos tipos de violência e, no VI CNP (Conselho Federal de Psicologia, 2007), o debate se concentra na atuação da Psicologia em áreas de vulnerabilidade social. Nos documentos referentes à edição mais recente, VIII CNP (Conselho Federal de Psicologia, 2013), podemos encontrar uma retomada das discussões feitas nos anos anteriores, reafirmando a promoção e a efetivação dos Direitos Humanos e a superação das diversas formas de violação de direitos e exclusão social, além da intenção de manter permanente debate sobre o tema da formação em Direitos Humanos em consonância com a Política Nacional de Educação em Direitos Humanos.

Conforme caderno de deliberações deste último CNP, nos próximos três anos, o Sistema Conselhos deve fortalecer, em parceria com os movimentos populares e sociais, a participação da Psicologia na luta pelos Direitos Humanos dos diversos segmentos sociais, apoiando políticas de ações afirmativas na garantia de direitos e cidadania, respeitando seus modos tradicionais de organização e de luta, no combate ao racismo, à discriminação e a toda e qualquer forma de violação de direitos, atento às normas legais. Além disso, deve manter o apoio, intensificar e promover ações e estratégias para a Comissão Nacional da Verdade nos estados brasileiros, fortalecendo como referência institucional os grupos de trabalho correlatos. Por fim, deve exercer posicionamento claramente contrário às políticas governamentais que rompem com a garantia de direitos. Ou seja, a discussão sobre a temática dos Direitos Humanos foi sistematicamente ampliada ao longo dos últimos anos e este processo deve ter continuidade nos próximos.

Esse movimento diz da relação estabelecida entre a Psicologia e os Direitos Humanos que, conforme Gonçalves (2010) remete ao contexto contraditório vivido no Brasil pós-ditadura em que se colocou a necessidade de afirmação dos direitos sociais diante do neoliberalismo. De acordo com Spink (2013), diante de um cenário no qual por longos períodos os direitos políticos foram cassados, os direitos civis eram e continuam sendo precários e os direitos sociais, construídos em fases populistas, restritos e longe de serem universais, não surpreende que a linguagem da transição democrática tenha sido a dos direitos. Entretanto, Coimbra, Knijnik e Galli (2013) ajudam a lembrar que o campo da elaboração das leis não é acessível a todos e que em diferentes situações, apesar de um direito de igualdade garantido pela Constituição de 1988, negros, pobres, moradores de comunidades de baixa renda, em especial os jovens, são tratados como animais, e seus locais de moradia referidos como 'fábricas de produzir bandidos' - o que os condena desde o berço a não serem humanos e, portanto, não serem contemplados pelos tratados nacionais e internacionais.

Diante disso, as autoras entendem que "O Estado, a serviço dos proprietários do capital econômico, é o maior violador de direitos, sustentado pelas estratégias de criminalização da pobreza assim como dos movimentos sociais" (Coimbra, Knijnik \& Galli, 2013, p. 46), sendo este mesmo Estado aquele que "em nome de certas garantias, implementa políticas higienistas e violentas direcionadas a uma determinada população" (p. 47). Analisando o papel da violência de Estado, Bicalho (2013) também oferece reflexões que desestabilizam nossos discursos pautados, em tese, na garantia de direitos, questionando "Até quando vamos continuar fingindo que não sabemos que, neste momento, alguém está sendo torturado neste país? E até quando continuaremos a não questionar 'que não-humanos' são esses e de que cidadania está se falando - e se fazendo? E, efetivamente, para quem?" (Bicalho, 2013, p. 32).

Considerando o que apontam Coimbra et al. (2013), assim como as provocações de Bicalho (2013), 
pode se questionar se quando psicólogos(as) colocam "práticas profissionais a serviço da garantia de direitos", como incita o tema do VIII CNP (Conselho Federal de Psicologia, 2013) e a partir desse discurso se alinham ao Estado, estão se propondo a trabalhar por transformação social de fato. Interrogamos se estamos comprometidos com práticas de liberdade ou com relações mantenedoras das condições de vida da população que agora assistimos, atualizando compromissos historicamente assumidos pela profissão. Estas questões são colocadas compartilhando com Dimenstein (2013) a crença de que é vital a disposição a uma atitude crítica sobre si mesmo, sobre o mundo e sobre nossa inserção neste mundo para escapar das aderências instituídas que nos levam a operar tecnologias de equilíbrio social.

As reflexões articuladas a partir deste marcador apontam para a necessidade de complexificarmos este debate acerca dos Direitos Humanos, indo além de simplesmente reproduzir o discurso de defesa, promoção ou garantia. Há algo que ainda não compartilhamos: a ideia de quem é humano, de para quem são os direitos. Há algo que ainda não colocamos em evidência: que práticas se sustentam a partir desse discurso, que garantias de fato tem sido possíveis. Há algo que ainda não aceitamos: que a Psicologia, sozinha, não conta com teorias, técnicas, instrumentos, intervenções que possibilitem tomar a garantia de direitos como objeto, de modo minimamente coerente e responsável. Temos vivido processos intensos de judicialização da vida que transferem para o âmbito da lei aquilo que diz de posturas éticas, como se fosse possível uma instância substituir a outra. Ao mesmo tempo, temos muitos profissionais envolvidos em relações com o judiciário que, longe de garantir direitos, contribuem com movimentos de patologização, adaptação, criminalização, controle. Parece necessário olhar para o percurso transcorrido até aqui e abrir novamente esse discurso para que algo novo seja criado a partir dele. Desmontar, repensar, problematizar, transgredir... Em busca de outros efeitos.

\section{Congresso Nacional de Psicologia e políticas públicas: o velho novo campo de atuação}

Por fim, as análises viabilizadas pelos cadernos de deliberações apontam que o tema das Políticas Públicas vem sendo debatido desde o II CNP (Conselho Federal de Psicologia, 1996), inicialmente abordado em relação à formação em Psicologia, mas ganhando maior dimensão a partir do III CNP (Conselho Federal de Psicologia, 2014), no qual se mostrou presente desde o tema: "Psicologia: interfaces - políticas públicas - globalização”, com pautas que foram continuamente abordadas a partir desse momento. Assim como os Direitos Humanos, as Políticas Públicas foram se consolidando enquanto referência para a discussão sobre os rumos da Psicologia em sua inserção social e como forma de materializar o Compromisso Social da Psicologia. Conforme Gonçalves (2010), a defesa de políticas públicas fala do compromisso com a construção de uma sociedade democrática e que respeita os direitos sociais. Ao mesmo tempo, segundo a autora, é preciso reconhecer que se fala de políticas públicas relativas a direitos sociais em uma sociedade desigual. O campo das políticas públicas sociais, em especial, envolve o paradoxo de ter referências constitucionais para sua ampliação e criação de sistemas de garantias de direitos, ao mesmo tempo em que as investidas neoliberais retardam e muitas vezes impedem o avanço de algumas conquistas sociais - ou seja, é um campo que se constitui na contradição.

Entendidas por Oliveira (2012) como dispositivos híbridos que, ao mesmo tempo em que buscam romper com os ciclos que geram a pobreza, não provocam alterações significativas nas condições de vida da sua população-alvo, as políticas públicas sociais como o SUAS, por exemplo, exigem, portanto, não apenas um conhecimento da política ou das diretrizes que a organizam, mas também de aspectos que estão fora do escopo do que a Psicologia delimitou em seus campos de saber exigindo a criação de novos conhecimentos e uma mudança na cultura profissional. Além disso, uma série de articulações entre Psicologia e Estado, de processos de negociação com as diversas esferas, tanto para garantir a presença do psicólogo em equipes, quanto para viabilizar seu trabalho em programas e serviços nos quais já está inserido - como as que podemos identificar nos cadernos do V CNP (Conselho Federal de Psicologia, 2004) quando debatida a efetivação das Políticas Públicas em Saúde/saúde mental.

A análise dos cadernos evidencia também a preocupação apontada no início do artigo com o modo como o exercício profissional tem se dado nesse contexto. No VI CNP (Conselho Federal de Psicologia, 2007), a partir da experiência do Banco Social, encontra-se a primeira referência à sistematização de referências para atuação profissional da Psicologia em diferentes contextos via Crepop. Esse tema é reto- 
mado através de eixo específico no VIII CNP (Conselho Federal de Psicologia, 2013), a partir da necessidade de garantir fortalecer e ampliar o Crepop como instância permanente de pesquisa e qualificação do exercício profissional. Mas pensamos que esta qualificação está diretamente associada a uma necessidade de politização do espaço das políticas públicas e da própria inserção da Psicologia no campo, de modo que seja menos ingênua. Se o Compromisso Social emergiu em um momento histórico onde a Psicologia militante se opunha ao Estado, em um movimento de resistência em direção à garantia de direitos, à medida que o Estado foi também se comprometendo em alguma medida com essa garantia de direitos, outras posturas tiveram que ser inventadas, assumidas.

O discurso do Compromisso Social parece favorecer uma postura na qual a Psicologia se mostra engajada politicamente com a transformação social, mas, ao mesmo tempo, negocia com o Estado para ampliar seu campo de atuação profissional. Compreendemos que esta postura seja estratégica para as representações institucionais da profissão no diálogo com os agentes que representam a gestão do Estado, em busca de pontos de convergência entre interesses dos profissionais e interesses da sociedade. Entretanto, em um momento histórico no qual estamos vivendo um forte retorno de movimentos conservadores e a sociedade em geral tem acolhido e apoiado manifestações da violência de Estado, fica evidente a necessidade de reflexão sobre até onde ir nesse processo e se ele é capaz de propiciar as transformações que a profissão tem pautado.

Nesse contexto, o debate referente às políticas públicas - que se evidencia como o mais antigo no que diz respeito ao Compromisso Social da Psicologia - mostra-se ainda recente para a profissão, e bastante complexo. Seguem sendo necessárias as problematizações não apenas sobre como entrar ou permanecer no campo, mas sobre o que fazer e como fazer estando nele. As experiências no SUAS talvez estejam sendo as mais radicais até o momento no sentido de colocar em questão não apenas o modelo de atenção oferecido pela Psicologia, mas os compromissos que assume através deles. Entendemos que sejam, por isso, potentes espaços de criação de brechas na medida em que sejam reconhecidas como parte de um dispositivo de controle em que diversos interesses estão em jogo - e não como boas ou más em si mesmas.

\section{Considerações finais}

As reflexões articuladas a partir da análise dos cadernos de deliberações dos CNPs - aqui apresentadas através dos marcadores Compromisso Social, Direitos Humanos e Políticas Públicas - buscam atentar para a complexidade que atravessa as práticas psicológicas no campo das políticas sociais públicas quando a garantia de direitos passa a se configurar como objeto para a profissão. Desnaturalizar o discurso Compromisso Social da Psicologia e colocá-lo novamente como produção histórica de um momento específico da Psicologia no Brasil evidenciando as condições que permitiram sua emergência enquanto dimensão de saber que constitui as redes no contexto das políticas públicas, como elemento que constitui as práticas da Psicologia no SUAS, é um exercício que pretende contribuir para que o processo por ele defendido siga em movimento e não se cristalize em formas já conhecidas.

Nesse exercício, três pontos precisam ser considerados com maior atenção. Primeiro, a institucionalização do discurso do Compromisso Social - que não necessariamente se converte em práticas comprometidas socialmente, mas pode servir para dar um tom politicamente correto a antigas práticas. Segundo, a ampliação da luta por Direitos Humanos que não parece acompanhada da reflexão acerca de quem são os humanos no contemporâneo, podendo ser desviada para movimentos de judicialização da vida. Terceiro, a compreensão das Políticas Públicas enquanto mercado de trabalho e possibilidade de engajamento político para os psicólogos, favorecendo a atualização de compromissos entre Psicologia e Estado que precisam ser revisados, revisitados, no contexto político atual. Estes pontos apontam para movimentos que se dão na esteira da construção da garantia de direitos como objeto para a profissão e, portanto, movimentos a partir dos quais se constroem, também, as práticas da Psicologia no campo da Assistência Social. Movimentos estes que podem colocar a Psicologia a serviço de um antigo compromisso de manutenção de determinado equilíbrio social e, ao mesmo tempo, a serviço de um compromisso ético e político com transformações nas condições de vida da população. Um quadro que carrega em si a ambivalência e a necessidade de constantes problematizações das verdades que o sustentam, das práticas que instituem, das subjetividades que produzem. 


\section{Referências}

Albanezi, R. M. B. (2008). Funcionamento democrático do Sistema Conselhos de Psicologia: CNP/APAF. In Conselho Federal de Psicologia. Democratização no Sistema Conselhos de Psicologia. Brasília, DF: CFP.

Bicalho, P. P. G. (2013). Ditadura e democracia: qual o papel da violência de Estado? In Conselho Regional de Psicologia do Rio Grande do Sul. Entre garantia de direitos e práticas libertárias. Porto Alegre, RS: CRPRS.

Bicalho, P. P. G. (2011). Ética e direitos humanos sob o crivo da avaliação psicológica: validade e fidedignidade em questão. In Conselho Federal de Psicologia. Ano da avaliação psicológica: textos geradores. Brasília, DF: CFP.

Bock, A. M. B., Ferreira, M. R., Gonçalves, M. G., \& Furtado, O. (2007). Silvia Lane e o projeto do "Compromisso Social da Psicologia”. Psicologia e Sociedade, 19(n. esp. 2): 46-56. https://doi.org/10.1590/S0102-71822007000500018

Brasil. (2004, 28 de outubro). Conselho Nacional de Assistência Social. Resolução No 145, de 15 de outubro de 2004. Diário Oficial da União.

Brasil. (1988). Constituição da Republica Federativa do Brasil (27a ed.). São Paulo, SP: Saraiva.

Brasil. (1993, 31 de dezembro). Lei No 8.142, de 28 de dezembro de 1993. Dispõe sobre a participação da comunidade na gestão do Sistema Único de Saúde (SUS) e sobre as transferências intergovernamentais de recursos financeiros na área da saúde e dá outras providências. Diário Oficial da União.

Brasil. (2011, 7 de julho). Lei No 12.435, de 6 de julho de 2011. Altera a Lei nº 8.742, de 7 de dezembro de 1993, dispõe sobre a organização da Assistência Social. Diário Oficial da União.

Brasil. (2006). Ministério do Desenvolvimento Social e Combate à Fome. Secretaria Nacional de Assistência Social. Norma operacional básica de recursos humanos do SUAS - NOB RH /SUAS. Brasília, DF: o autor.

Brasil. (2005). Ministério do Desenvolvimento Social e Combate à Fome. Secretaria Nacional de Assistência Social. Política Nacional de Assistência Social - PNAS 2004; Norma Operacional Básica NOB /SUAS. Brasília, DF: o autor.

Brasil. (2009). Ministério do Desenvolvimento Social e Combate à Fome. Secretaria Nacional de Assistência Social. Tipificação nacional dos serviços socioassistenciais. Brasília, DF: o autor.

Coimbra, C., Knijnik, L., \& Galli, T. (2013). Qual a cor da farda dos guardiões da ordem? Algumas problematizações sobre a história do Brasil contemporâneo. In Conselho Regional de Psicologia do Rio Grande do Sul. Entre garantia de direitos e práticas libertárias (pp. 43-57). Porto Alegre, RS: CRPRS.

Conselho Federal de Psicologia. (2005). Banco social de serviços: relatório final. Brasília, DF: o autor.

Conselho Federal de Psicologia. (2004). Caderno de Deliberações do V CNP. Recuperado de http://site.cfp.org.br/ wp-content/uploads/2004/12/relatorio_vcnp.pdf

Conselho Federal de Psicologia. (2013). Caderno de Deliberações do VIII CNP. Brasília,DF: o autor. Recuperado de http://site.cfp.org.br/wp-content/uploads/2013/08/MinutaCadernodelibera\%C3\%A7oes14.08.pdf

Conselho Federal de Psicologia. (2014). Caderno de Deliberações do III CNP. Brasília, DF: o autor. Recuperado de http://site.cfp.org.br/wp-content/uploads/2014/06/Caderno-de-Delibera\%C3\%A7\%C3\%B5es-do-III-CNP.pdf

Conselho Federal de Psicologia. (2001). Caderno Síntese das Deliberações do IV CNP. Recuperado de http://www2. pol.org.br/satepsi/CD_testes/pdf/IV\%20CNP\%20-\%20Caderno\%20deliberacoes.pdf

Conselho Federal de Psicologia. (2011). Como os psicólogos e as psicólogas podem contribuir para avançar o Sistema Único de Assistência Social (Suas): informações para gestoras e gestores. Recuperado de http://crepop.pol.org.br/ novo/wp-content/uploads/2011/12/GestoresSuasfinanl-corrigido.pdf

Conselho Federal de Psicologia. (1996). Documento do II Congresso Nacional de Psicologia, 28 de agosto a $1^{\circ}$ de setembro, Belo Horizonte. Recuperado de http://abepsi.org.br/wp-content/uploads/2011/07/1996-documentodo2congressonacionaldepsicologia.pdf

Conselho Federal de Psicologia. (2009). Serviço de proteção social a crianças e adolescentes vítimas de violência, abuso e exploração sexual e suas famílias: referências para atuação do psicólogo. Recuperado de http://site.cfp. org.br/wp-content/uploads/2009/10/CREPOP_Servico_Exploracao_Sexual.pdf

Conselho Federal de Psicologia. (2007). VI Seminário Nacional de Psicologia e Políticas Públicas: relatório. Maceió, AL: o autor. Retirado de http://site.cfp.org.br/wp-content/uploads/2007/10/politicas_publicas_cartilha.pdf 
Conselho Federal de Psicologia. (2012). Referências técnicas para atuação de Psicólogas(os) em medidas socioeducativas em meio aberto. Recuperado de http://crepop.pol.org.br/novo/wp-content/uploads/2012/10/ Atua\%C3\%A7\%C3\%A3o-dasos-Psic\%C3\%B3logasos-em-Programas-de-Medidas-Socioeducativas-em-Meio-Aberto.pdf

Conselho Federal de Serviço Social. (2007). Parâmetro para atuação de assistentes sociais e psicólogos(as) na Política de Assistência Social. Brasília, DF: o autor. Recuperado de http://www.cress-es.org.br/site/images/cartilha_ cfess_final_grafica.pdf

Dimenstein, M. (2013). Prefácio: práticas e políticas publicas: a vida que emerge na adversidade. In L. R. Cruz, L. R. Rodrigues, \& N. M. F. Guareschi, Interlocuções entre a psicologia e a política nacional de assistência social. Santa Cruz do Sul, SC: EDUNISC.

Foucault, M. (2012). A ordem do discurso: aula inaugural no Collège de France, pronunciada em 02 de dezembro de 1970 (L. F. A. Sampaio, trad., 22a ed.). São Paulo, SP: Loyola. (Original publicado em 1970).

Foucault, M. (2012). A poeira na nuvem. In Foucault, M. Estratégia, poder, saber. Rio de Janeiro, RJ: Forense Universitária. (Original publicado em 1980).

Freitas, M. F. Q. (2003). Dinâmica comunitária e práticas psicossociais: significados e avanços na perspectiva dos atores envolvidos. In Anais do XII Encontro Nacional da ABRAPSO (pp.118-119). Porto Alegre: ABRAPSO.

Gonçalves, M. G. M. (2010). Psicologia, subjetividade e políticas públicas. São Paulo, SP: Cortez.

Gros, F. (2011). Situação do curso. In M. Foucault. A coragem da verdade: o governo de si e dos outros II: curso no Collège de France (1983-1984) (E. Brandão, trad.). São Paulo, SP: Martins Fontes.

Gros, F. (2004). Situação do curso. In M. Foucault. A hermenêutica do sujeito (M. A, Fonseca, Muchail D. T., trads.). São Paulo, SP: Martins Fontes.

Leite, W. S. (2008). Lei 5.766: uma cara conquista. In Conselho Federal de Psicologia. Democratização no Sistema Conselhos de Psicologia (pp. 10-13). Brasília, DF: CFP.

Lockmann, K. (2013). A proliferação das políticas de assistência social na educação escolarizada: estratégias da governamentalidade neoliberal (Tese de doutorado). Universidade Federal do Rio Grande do Sul, Porto Alegre, RS.

Lopes, A. (2005). O compromisso social dos psicólogos brasileiros evidenciado nas publicações da revista Psicologia Ciência e Profissão (Dissertação de mestrado). Universidade Federal de Santa Catarina, Florianópolis, SC.

Macedo, J. P. S. (2007). O Psicólogo no campo do bem-estar: cartografias de práticas na Saúde e Assistência Social (Dissertação de mestrado). Universidade Federal do Rio Grande do Norte, Natal, RN.

Moraes, T. D., \& Nascimento, M. L. (2002). Da norma ao risco: transformações na produção de subjetividades contemporâneas. Psicologia em Estudo, 7(1): 91-102. https://doi.org/10.1590/S1413-73722002000100012

Oliveira, I. F. (2012). Os desafios e limites para a atuação do psicólogo no Suas. In L. Cruz, \& N. M. F. Guareschi (Org.), O psicólogo e as políticas públicas de assistência social (pp. 35-51). Rio de Janeiro, RJ: Vozes.

Oliveira, I. F., \& Amorim, K. M. (2012). Psicologia e política sócial: o trato da probreza como "sujeito psicológico". Psicologia e Argumento, 30(70): 559-566. Retirado de http://www2.pucpr.br/reol/pb/index.php/pa?ddl=6142\&dd99=view\&dd98=pb

Pereira, V. T. (2013). A psicologia no mundo da vida: representações sociais sobre os (as) usuários (as) do CRAS (Dissertação de mestrado). Universidade Federal do Rio Grande do Sul, Porto Alegre, RS.

Prado Filho, K., \& Martins, S. (2007). A subjetividade como objeto da(s) psicologia(s). Psicologia \& Sociedade, 19(3): 14-19. https://doi.org/10.1590/S0102-71822007000300003

Reis, C., Giugliani, S., \& Pasini, V. (2012). Conversando sobre a Psicologia e o Suas: potencialidades e desafios para a atuação profissional dos psicólogos na política de assistência social. In L. Cruz, \& N. M. F. Guareschi (Orgs.), O psicólogo e as políticas públicas de assistência social (pp. 149-166). Petrópolis, RJ: Vozes.

Scarparo, H., \& Guareschi, N. (2007). Psicologia Social comunitária profissional. Psicologia \& Sociedade, 19(Edição Especial 2): 100-108. https://doi.org/10.1590/S0102-71822007000500025

Spink, P. (2013). Prefácio. In A. L. Brizola, A. V. Zanella, \& M. Gesser (Orgs.), Práticas sociais, políticas públicas e direitos humanos (pp. 11-14). Florianópolis, SC: ABRAPSO. 
Psicologia: Ciência e Profissão Abr/Jun. 2017 v. 37 n², 349-362.

Trein, A. L. (2012). “O que estamos fazendo aqui?” Sobre o pesquisar e a autonomia nos jogos de visibilidade do SUAS (Dissertação de mestrado). Universidade Federal do Rio Grande do Sul, Porto Alegre, RS.

Alessandra Xavier Miron

Mestre em Psicologia Social e Institucional - UFRGS

E-mail: alessandramiron@gmail.com

Neuza Maria de Fátima Guareschi

Doutora em Educação - UFRGS

E-mail: nmguares@gmail.com

Endereço para envio de correspondência:

Universidade Federal do Rio Grande do Sul, Departamento de Psicologia.

Av. Ramiro Barcelos 2600. Santana. CEP: 90035-003

Porto Alegre - RS, Brasil.

Telefone: (51) $33085954 \backslash$ Fax: (51) 33085954

Recebido: 25/06/2014 Data de Reformulação: 26/04/2017 Aprovado: 26/04/2017

Recebido 25/06/2014

Reformulação 26/04/2017

Aprovado 26/04/2017

Received 06/25/2014

Reformulated $04 / 26 / 2017$

Approved 04/26/2017

Recebido 25/06/2014

Reformulado 26/04/2017

Aceptado 26/04/2017

Como citar: Miron, A.X., \& Guareschi N. M. F. (2017). Compromisso social da Psicologia e Sistema Único de Assistência Social: possíveis articulações. Psicologia: Ciência e Profissão, 37(2), 349-362. https://doi.org/10.1590/1982-3703000952014

How to cite: Miron, A.X., \& Guareschi N. M. F. (2017). Social commitment of Psychology and Unified Social Assistance System: possible articulations. Psicologia: Ciência e Profissão, 37(2), 349-362. https://doi.org/10.1590/1982-3703000952014

Cómo citar: Miron, A.X., \& Guareschi N. M. F. (2017). Compromiso social y Sistema Único de Asistencia Social: Posibles Articulaciones. Psicologia:Ciência e Profissão, 37(2), 349-362. https://doi.org/10.1590/1982-3703000952014 